\title{
Effect of Precipitation on Hot Deformation Behavior and Processing Maps of Nickel-Base UNS N10276 Alloy
}

\author{
En-Xiang Pu ${ }^{1,2} \cdot$ Wen-Jie Zheng ${ }^{2} \cdot$ Zhi-Gang Song $^{2} \cdot$ Han Feng ${ }^{2} \cdot$ Han Dong ${ }^{2}$
}

Received: 12 April 2017/Revised: 15 May 2017/Published online: 14 August 2017

(C) The Chinese Society for Metals and Springer-Verlag GmbH Germany 2017

\begin{abstract}
The hot deformation characteristics and processing maps of aged nickel-base UNS N10276 alloy were investigated and compared with those of solution-treated UNS N10276 alloy at temperatures of $950-1250{ }^{\circ} \mathrm{C}$ and strain rates between 0.01 and $10 \mathrm{~s}^{-1}$. The dominant precipitated phase in the aged alloy was identified as topologically close-packed (TCP) $\mu$ phase enriched in Mo and Ni. The precipitates present in the UNS N10276 alloy could significantly facilitate flow softening after peak stress at temperatures lower than $1150{ }^{\circ} \mathrm{C}$ and strain rates higher than $0.01 \mathrm{~s}^{-1}$. Processing maps at true strains of 0.1-0.9 were developed using the dynamic materials model and experimental flow stress data. Although aging treatment slightly shrank the suitable hot working window of this alloy, the aged alloy showed higher peak efficiencies of power dissipation and smaller unstable regions in comparison with solution-treated alloy. Furthermore, aging treatment eliminated the instability region of processing maps at true strains of $0.2-0.5$. The precipitated phase promoted dynamic recrystallization (DRX) by the particle-stimulated nucleation (PSN) mechanism, which resulted in the larger fraction of DRX as well as finer and more uniform grain structure in the aged alloy specimens compared to the solution-treated alloy.
\end{abstract}

KEY WORDS: UNS N10276 alloy; Precipitation; Hot deformation; Processing map

\section{Introduction}

The high-performance alloy UNS N10276 is a wrought nickel-base superalloy that is strengthened by solute elements and has been used for the manufacture of rotor and stator shielding in the nuclear reactor coolant pump of

Available online at http://link.springer.com/journal/40195

Wen-Jie Zheng

sxzwj163@163.com

En-Xiang $\mathrm{Pu}$

pexzhaotong@163.com

1 School of Materials Science and Engineering, Tsinghua University, Beijing 100084, China

2 Central Iron and Steel Research Institute, Beijing 100081, China
AP1000 advanced passive plant [1]. Moreover, it is intended for use in chemical processing, pollution control and aerospace industries because of its excellent properties [2]. In order to improve its corrosion resistance and hightemperature strength, this alloy contains high levels of the refractory metal elements, such as $\mathrm{Mo}, \mathrm{Cr}$ and $\mathrm{W}$, which may render it prone to the precipitation of topologically close-packed (TCP) intermetallic phases during exposure to susceptible precipitation temperature. It has been reported in our previous study that the alloy UNS N10276 has relatively faster precipitation kinetics in the temperature range from 760 to $980{ }^{\circ} \mathrm{C}$, and the second phase in this alloy could be dissolved completely at temperatures higher than $1150{ }^{\circ} \mathrm{C}$ [3]. Moreover, solution treatment was suggested to be in the temperature range from 1150 to $1200{ }^{\circ} \mathrm{C}$. Investigations in previous published reports have identified three distinct second phases in alloy UNS N10276, and they are TCP $\mu$ phase, $M_{6} \mathrm{C}$ carbides and $\mathrm{P}$ 
phase, respectively, all of which are very rich in Mo, W and Ni. The amount of $\mu$ phase is much larger than that of $M_{6} \mathrm{C}$ and $\mathrm{P}$ phase [4]. The $\mu$ phase is known to be hard and brittle, which has deleterious effects on low-temperature tensile and impact toughness as well as high-temperature creep properties, and hence the occurrence of this phases is undesirable [5]. This is ascribed to that the TCP phase may act as barriers to moving dislocations, which pileup at the precipitate interface, leading to interfacial decohesion, crack initiation and catastrophic failure of components [6]. Although a number of studies stated that precipitation of the TCP phase should be avoided during service or hot deformation for the alloy UNS N10276 [7, 8], the investigation reported by Liu et al. [9] reveals that the $\mu$ phase formed after aging treatment can improve high-temperature tensile plasticity of this alloy. However, the information on whether the $\mu$ phase could bring benefit to hot workability of the alloy UNS N10276 is not available in the published literature.

Successful application of the alloy UNS N10276 in nuclear industries was attributed to the feasibility of hot working, such as forging and rolling for large billet of this alloy, since hot working is a crucial step to manufacture critical component. Appropriate combination of hot deformation parameters (temperature, strain rate and strain) is the precondition to obtain desired microstructure and mechanical properties for wrought nickel-base alloy. Over the past three decades, processing map has been verified as an effective method to understand the hot working characteristics of various alloys, such as nickel-base alloy [10-15], austenitic stainless steel [16, 17], aluminum alloys [18], copper alloys [19]. Although hot deformation behavior of solution-treated alloy UNS10276 has been systematically investigated using processing map in our laboratory [1] and previous studies [20, 21], the question of the effect of precipitated phase on hot deformation characteristics of this alloy is still open. In the present investigation, hot compression tests were performed on solutiontreated and aged UNS N10276 alloys in a wide range of deformation temperatures and strain rates. Processing maps for both alloys were established. Our attention was focused on the role played by the precipitates in hot deformation process of this alloy. It was demonstrated that the second phases were not detrimental to the hot workability of the alloy studied, but exhibited favorable influence.

\section{Experimental}

The material used in this study is nickel-base UNS N10276 alloy, whose chemical compositions (wt\%) are as follows: $0.01 \mathrm{C}, 15.6 \mathrm{Cr}, 16.08 \mathrm{Mo}, 3.8 \mathrm{~W}, 5.2 \mathrm{Fe}, 0.5 \mathrm{Mn}, 0.22 \mathrm{Al}$, $0.08 \mathrm{Si}, 0.02 \mathrm{Co}, 0.005 \mathrm{P}, 0.002 \mathrm{~S}$ and $\mathrm{Ni}$ (balance). The alloy was melted in a vacuum induction melting (VIM) furnace and refined by electroslag remelting (ESR). Then, the ESR ingot was homogenized at $1200{ }^{\circ} \mathrm{C}$ for $30 \mathrm{~h}$ followed by hot forging and rolling at the same temperature to the final thickness of $15 \mathrm{~mm}$. After that, the hot-rolled alloy was heat treated: (1) solution treated at $1180{ }^{\circ} \mathrm{C}$ for $1 \mathrm{~h}$ and water quenched, designated as ST; (2) ST alloy aged at $870{ }^{\circ} \mathrm{C}$ for $24 \mathrm{~h}$ and air-cooled, designated as STA. The microstructure formed during aging was characterized by a variety of techniques, such as optical metallography, scanning electron microscopy (SEM), electron probe microanalysis (EPMA) and transmission electron microscopy (TEM). The phases that possibly form in the UNS N10276 alloy under equilibrium condition were calculated using Thermo-Calc software in association with the $\mathrm{Ni}$ DATA database (version 8).

Cylindrical compression samples with $15 \mathrm{~mm}$ in height and $8 \mathrm{~mm}$ in diameter were machined from both solutiontreated and aged alloys with their axes parallel to rolling direction. Isothermal compression tests were performed on a Gleeble 3800 thermomechanical simulator at $950-1250{ }^{\circ} \mathrm{C}$ and strain rates between 0.01 and $10 \mathrm{~s}^{-1}$. To minimize the friction, graphite foils sprayed with boron nitride were used as a lubricant between specimens and anvils. Prior to compression, the specimens were heated to deformation temperature at a rate of $20^{\circ} \mathrm{C} \mathrm{s}^{-1}$ and held at this temperature for $120 \mathrm{~s}$. The samples were compressed to true strain of 1.0. The deformed specimens were immediately quenched in water to preserve the high-temperature microstructure. The deformed specimens were sliced along the compression axis for electron backscatter diffraction (EBSD) analysis. FEI Quanta 650FEG scanning electron microscope coupled with a fully automated HKL Technology EBSD attachment was employed to characterize the deformed microstructure. Scans were performed over an area of $250 \mu \mathrm{m} \times 250 \mu \mathrm{m}$ with a step size of $0.3-1.5 \mu \mathrm{m}$ depending on the grain size. EBSD data were analyzed by Tango program in the Channel 5 software.

\section{Results and Discussion}

\subsection{Characterization of the Initial Microstructures}

Figure 1 shows the optical micrographs of solution-treated (ST) and aged (STA) UNS N10276 alloys. The ST alloy (Fig. 1a) exhibited clean grain boundaries and grain interiors with average grain size of $243 \mu \mathrm{m}$, indicating that solution treatment has completely dissolved the second phase precipitated during hot rolling. As expected, upon aging the ST alloy at $870{ }^{\circ} \mathrm{C}$ for $24 \mathrm{~h}$, a large amount of precipitates nucleated heterogeneously at grain and annealing twin boundaries as well as within grain interiors 

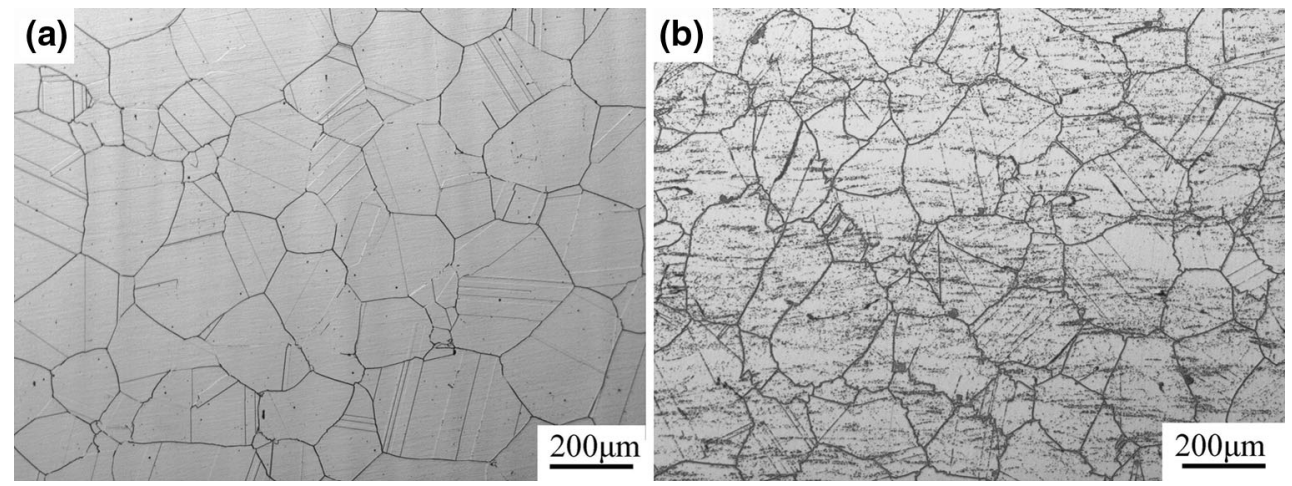

Fig. 1 Starting microstructures of a the solution-treated (ST), b the aged (STA) UNS N10276 alloys

(Fig. 1b). The average grain size of STA alloy was measured to be $245 \mu \mathrm{m}$, which is very close to that of ST alloy.

The types of phases and their phase fraction in the UNS N10276 alloy were calculated using equilibrium modes, as indicated in Fig. 2. The thermodynamic equilibrium phases predicted in the alloy in the temperature range from 500 to $1130{ }^{\circ} \mathrm{C}$ were $\mu$ phase, $M_{6} \mathrm{C}, \sigma$ phase and $M_{23} \mathrm{C}_{6}$. The compositions of these phases predicted are very rich in Mo and Ni. Mole fraction (20.47\%) of $\mu$ precipitates was much higher than that $(0.32 \%)$ of $M_{6} \mathrm{C}$ carbides at $870{ }^{\circ} \mathrm{C}$. Therefore, $\mu$ precipitates are considered to act as main second phase to affect hot deformation. It is interesting to note that both the predicted $\sigma$ phase and $M_{23} \mathrm{C}_{6}$ have not been experimentally observed in the previous studies, whereas the $\mathrm{P}$ phase that has been verified to be formed during aging treatment at $870{ }^{\circ} \mathrm{C}$ was absent in the predicted phase. This may be due to the fact that $\sigma$ phase and $M_{23} \mathrm{C}_{6}$ were in quantities below the limit of detection, while $P$ phase was metastable phase, and thus it cannot be predicted by thermodynamic calculation under equilibrium condition.

The details of the precipitates morphology indicated in Fig. $1 \mathrm{~b}$ can be further observed in the SEM image shown in Fig. 3a. The precipitates appeared to have blocky, acicular or globular morphology. Energy-dispersive spectroscopy
(EDS) analysis randomly performed on twenty different precipitates suggests that the compositions of these phases are remarkably close, and they were extremely abundant in $\mathrm{Mo}$ and $\mathrm{Ni}$ with the modest levels of $\mathrm{W}, \mathrm{Cr}$ and $\mathrm{Fe}$ (Fig. 3b). Thus, it is difficult to identify unambiguously these phases only by EDS analysis in an SEM, and TEM examination is necessary. The representative TEM images and selected area diffraction patterns (SADP) obtained from the aged UNS N10276 alloy are shown in Fig. 4. From the SADP, TCP $\mu$ phase and $M_{6} \mathrm{C}$ carbides could be easily identified, but other types of the precipitates have not been detected. Based on TEM observation, the size of needle-type precipitates was measured to be $2-4 \mu \mathrm{m}$, while the blocky and globular ones had the size of $1-2 \mu \mathrm{m}$. It is shown that $\mu$ phase has intrinsic planar defect structure of stacking faults, which is characteristic of the $\mu$ phase and can be used as a prominent trait to identify the $\mu$ phase from other precipitates. For the $M_{6} \mathrm{C}$ carbides, it has no distinguishing feature. However, as suggested by Yang et al. [22], the precipitation of $\mu$ phase is strongly associated with $M_{6} \mathrm{C}$ carbide; nucleation of $\mu$ phase particles can occur adjacent to the $M_{6} \mathrm{C}$ carbides, where an abundance of $\mu$-forming elements such as $\mathrm{Mo}, \mathrm{Cr}, \mathrm{Fe}$ and $\mathrm{W}$ is expected.

The elemental concentration maps of the alloying elements using EPMA for the aged UNS N10276 alloy (STA)
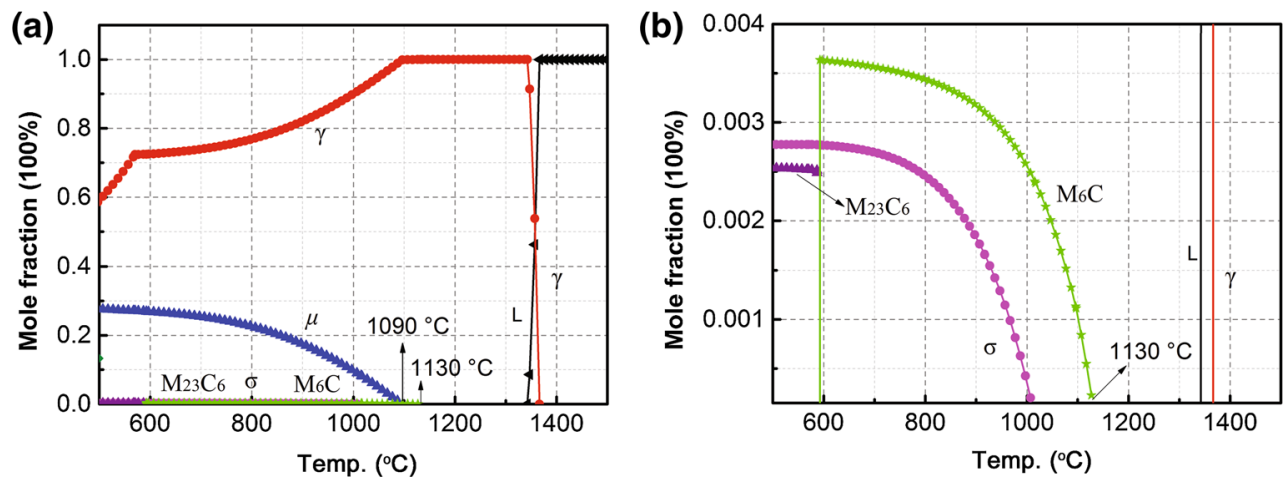

Fig. 2 Thermodynamic equilibrium stability and mole fraction of phases in UNS N10276 alloy between 500 and $1500{ }^{\circ} \mathrm{C}$ a, the higher magnification $\mathbf{b}$ 

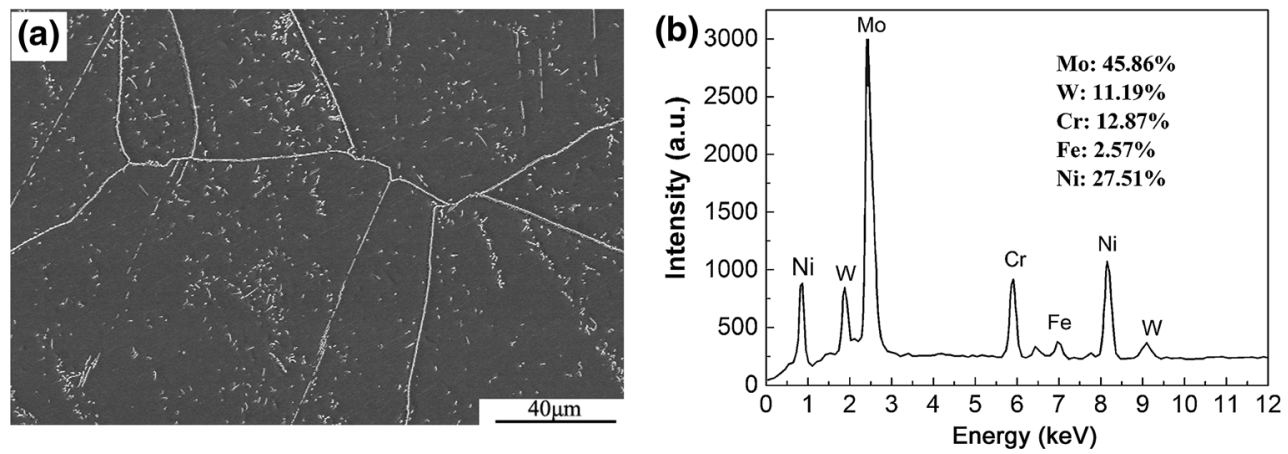

Fig. 3 a SEM image of the aged UNS N10276 alloy, b typical EDS spectra of precipitates
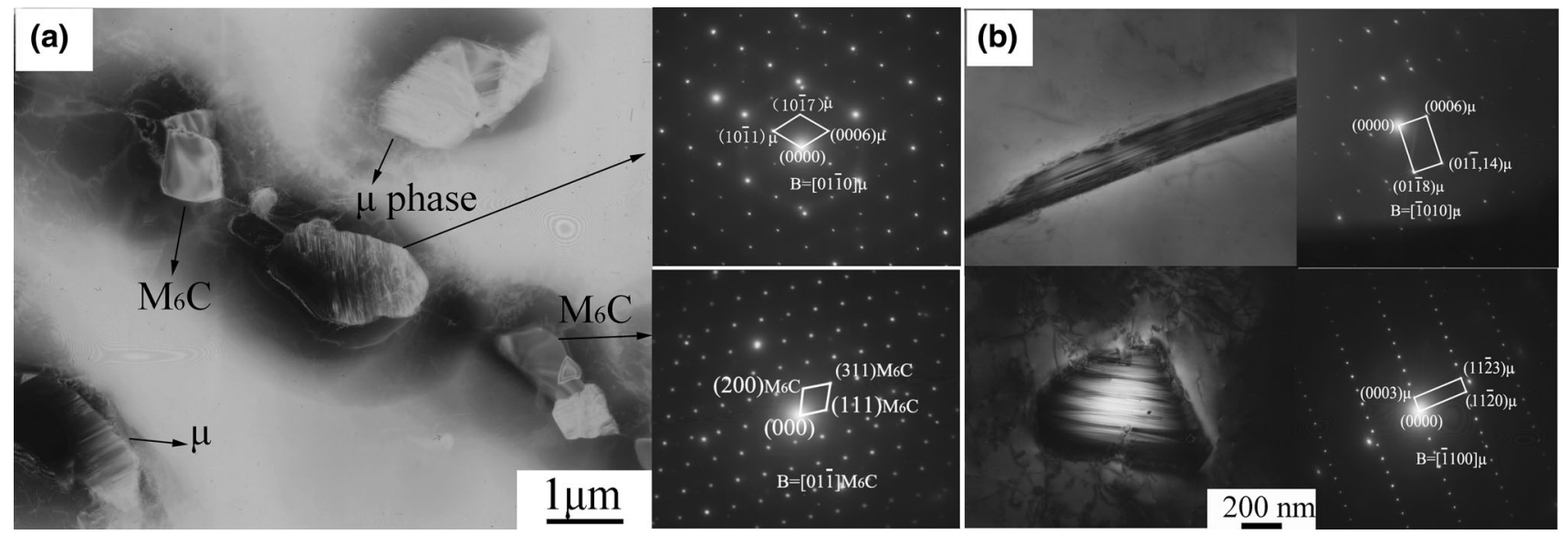

Fig. 4 TEM micrographs and selected area electron diffraction pattern of the precipitates in UNS N10276 alloy aged at $870{ }^{\circ} \mathrm{C}$ for $24 \mathrm{~h}$

are shown in Fig. 5. It is clear that Mo, $\mathrm{W}$ and Fe were partitioned inside both grain boundaries and grain interior precipitates, whereas $\mathrm{C}$ was mainly concentrated in the precipitates formed intergranularly. This suggested $M_{6} \mathrm{C}$ carbides took place primarily on grain boundaries and twin boundaries, while $\mu$ phase precipitated in both grain boundaries and grain interior. Accordingly, TCP $\mu$ phase was further confirmed to be the dominant second phase in the STA alloy. For the Cr element, it is inclined to partition into the austenite matrix. From Fig. $5 \mathrm{c}$ and d, it can be observed that at the vicinity of the second-phase particles, the concentration of Mo and W element in the $\gamma$-matrix is much lower than normal alloy composition. This signifies that the precipitation of TCP phases depleted the potent solid solution strengthening elements from the austenite $\gamma$ matrix, as a result of which the matrix at elevated temperature could be softened.

\subsection{Influence of Precipitation on Flow Behavior of the UNS N10276 Alloy}

The representative true stress-true strain curves of ST and STA alloys are shown in Fig. 6. It can be observed that the flow curves of STA alloy have similar shape to those of ST alloy. For both alloy, the flow stress obtained under different hot compression conditions showed a relatively significant dependence on deformation temperature and strain rate, and increased with decreasing temperature and increasing strain rate. The flow stress increases rapidly up to a peak value under a peak strain (the strain corresponding to the maximum stress), showing a typical work hardening-dynamic recovery (WH-DRV) stage [23]. Two distinct differences in flow curves between ST and STA alloys could be found. Firstly, the STA alloy showed a higher work hardening rate and a shorter WH-DRV stage as well as smaller peak strain compared to ST alloy at temperatures lower than $1100{ }^{\circ} \mathrm{C}$ and strain rate higher than $0.1 \mathrm{~s}^{-1}$. Secondly, STA alloy exhibited much larger extent of strain softening after peak stress in comparison with ST alloy in the temperature range of $950-1150{ }^{\circ} \mathrm{C}$ and at strain rates higher than $0.01 \mathrm{~s}^{-1}$. Therefore, it can be concluded that the presence of TCP $\mu$ phase and $\mathrm{M}_{6} \mathrm{C}$ had a softening effect on the hot deformation of the UNS N10276 alloy, especially at the low temperatures and high strain rates. It has been reported that the delta phase $\left(\mathrm{Ni}_{3} \mathrm{Nb}\right)$ also has the same effects during the hot deformation of GH4169 superalloy [24]. In the case of hot compression above the dissolution temperature of the second phase (about 

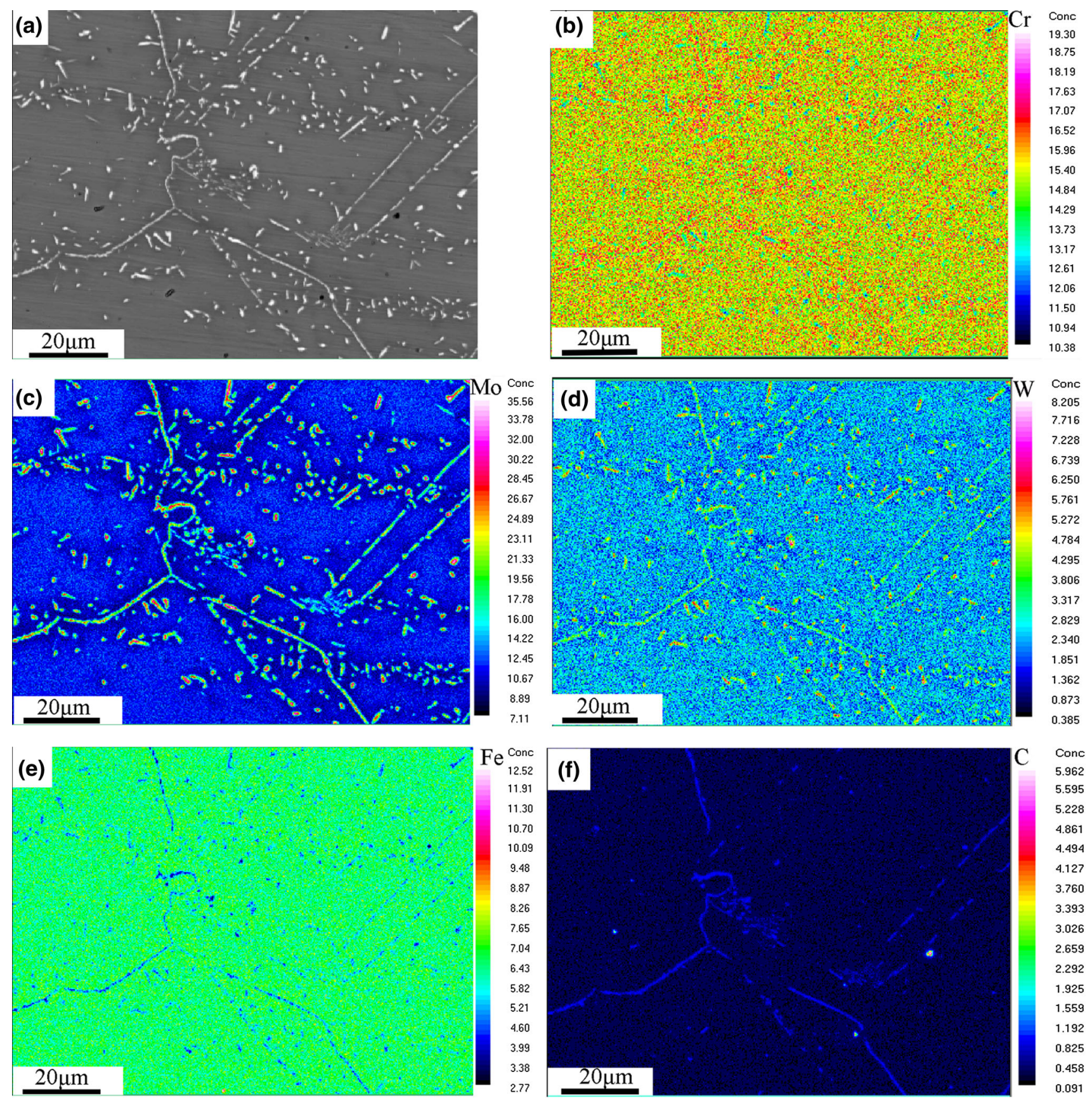

Fig. 5 EPMA elemental mapping of UNS N10276 alloy aged at $870{ }^{\circ} \mathrm{C}$ for 24 h: a SEM image; distribution maps of b Cr element, c Mo element, d W element, e Fe element, f $\mathrm{C}$ element

$1130{ }^{\circ} \mathrm{C}$ ) and at low strain rates, both dynamic recovery (DRV) and DRX occurred easily, and the second-phase particles were dissolved. Thus, the softening effect induced by precipitates was weakened at higher temperatures and lower strain rates.

The reason behind the flow softening being promoted by the presence of precipitates could be illustrated via following two distinct effect mechanisms. The first one is the particle-stimulated nucleation (PSN) mechanisms, which is operative when a particle size is larger than $1 \mu \mathrm{m}$ [25]. The precipitated particles in the STA alloy can accelerate the dislocation generation and accumulation, promoting formation of a plastically deformed zone around the precipitates through inducing stress concentration. Consequently, the presence of large, hard $\mu$ phase particles or $M_{6} \mathrm{C}$ during the hot deformation of the alloy could induce strong deformation gradients that are associated with both substructure refinement and lattice orientation gradients. As a 

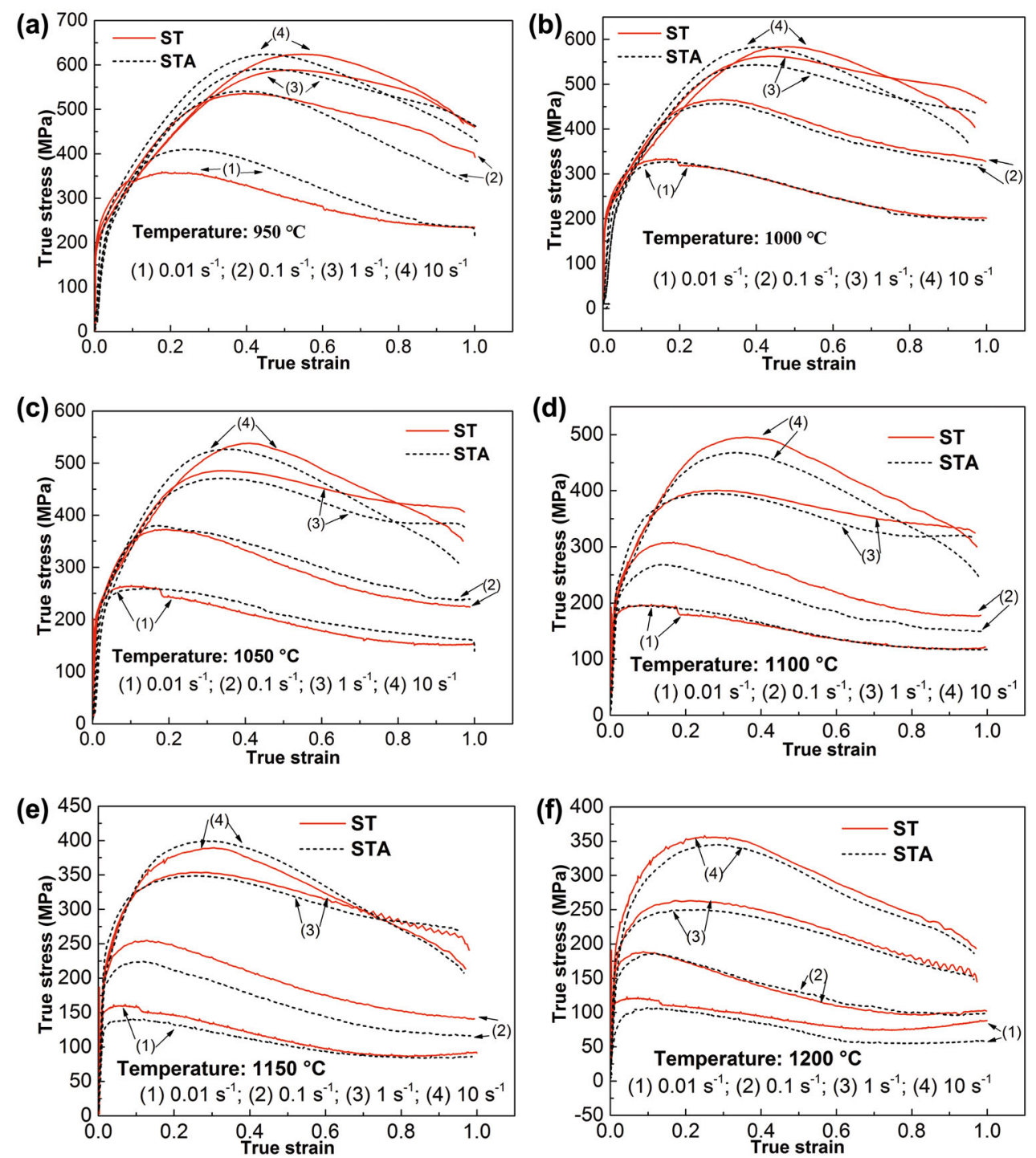

Fig. 6 True stress-true strain curves for the solution-treated (ST) and aged (STA) UNS N10276 alloys under different strain rates

result, the higher strain-stored energy and the larger driving force for DRX nucleation could be obtained during hot compression of STA alloy, which stimulates the occurrence of DRX, if the deformation temperature is below the dissolution temperature of $\mu$ phase and $M_{6} \mathrm{C}$. Since DRX is main softening mechanism for the alloys with low stacking fault energy like the UNS N10276 alloy, increasing extent of DRX could effectively decrease the flow stress. The second effect mechanism is the softening of the $\gamma$-matrix arising from its depletion in strengthening elements, such as Mo and $\mathrm{W}$, which enter in the TCP $\mu$ phase and $M_{6} \mathrm{C}$ carbide. It is believed that the presence of higher $\mathrm{Cr}$, Mo and $\mathrm{W}$ content in the $\gamma$-matrix lowers the staking fault energy resulting from the formation of widely spaced partial dislocation [1], and hence hot strength could be augmented. In addition, these refractory elements like Mo and $\mathrm{W}$ decrease the effective diffusion rate in the lattice and increase bonding energies between their atoms, which greatly aggrandize the activation energy for elements diffusion, and could also retard or suppress the recrystallization. Therefore, precipitations of the TCP $\mu$ phase and $M_{6} \mathrm{C}$ particles could effectively soften the alloy and make DRX easier to happen by reducing the concentration of Mo and $\mathrm{W}$ in the $\gamma$-matrix. Based on above analysis, it is safe for us to conclude that the precipitated particles exerted softening effect on the flow stress of the STA alloy through PSN mechanisms and plundering refractory elements in the $\gamma$ matrix.

It should be noted that the flow stress of ST alloy is higher than that of STA alloy at $950{ }^{\circ} \mathrm{C}$ and $0.01 \mathrm{~s}^{-1}$ (see Fig. 6a). Since both alloys have smaller critical strain for DRX at the lower strain rate and the rate of dislocation generation is much slower than that at the higher strain rate, the precipitated particles have insignificant effect on 
the driving force for DRX. Furthermore, the second phase could effectively harden the alloy by precipitation strengthening at the lower temperature and thus result in the larger flow stress during hot compression. However, both ST and STA alloys were very comparable in the flow stress when hot deformation was performed at temperatures higher than $1000{ }^{\circ} \mathrm{C}$ with strain rate of $0.01 \mathrm{~s}^{-1}$. This is attributed to the fact that DRX is easy to occur at the higher deformation temperature and the lower strain rate, and precipitation hardening effect was weakened to a large degree.

\subsection{Influence of Precipitation on DRX of the UNS N10276 Alloy}

It is expected that the PSN effect could significantly increase the degree of DRX and result in the formation of finer and more homogeneous grains in STA alloy. The typical microstructures of ST and STA alloys deformed below $1100{ }^{\circ} \mathrm{C}$ are shown in Figs. 7 and 8, respectively. As indicated in Fig. 7a-f, the microstructures in the deformed ST alloy consisted of coarse un-recrystallized grains and fine DRX grains, resembling classical "necklace structure." The formation of necklace-type microstructure resulted from preferential nucleation of DRX on initial grain boundaries and twinning boundaries. In our previous study [1], it has been demonstrated that discontinuous DRX involving distinct nucleation and growth stages is the dominant DRX mechanism of the ST alloy. As for STA alloy, the extent of DRX is much larger than that of ST alloy, and no observable "necklace structure" was formed under all hot deformation conditions. However, as indicated in Fig. 8a-f, large amounts of new DRX grains can be observed in the deformed grain interior (marked by the red arrows), which is associated with intragranular precipitates. That is to say, the nucleation of DRX in STA alloy not only took place along grain boundaries, but also occurred simultaneously within the grains, signifying that intragranular DRX nucleation was an important contributor to consume the deformed matrix during deformation as an indispensable DRX mechanism. This further provides the evidence for the occurrence of PSN mechanisms. Therefore, the compressed STA alloy samples inevitably possess the higher DRX nucleation rate compared to ST alloy, which increases the extent of DRX. As a result, finer and more uniform grains could be obtained, which has been verified by the microstructure comparison of deformed ST and STA alloys (see Figs. 7, 8). Moreover, since DRX is believed to be the most effective softening mechanism during hot deformation of the metal materials with low stacking fault energy [26-28], the STA alloy was expected to show more remarkable strain softening after peak stress in comparison with ST alloy. This is consistent with the information reflected from flow curves (see Fig. 6).

In order to further reveal the effect of precipitation on the DRX of the UNS N10276 alloy, the fraction of DRX was calculated by EBSD analysis software for the ST and STA alloys, as listed in Table 1. The values of DRX fraction were plotted against temperature and strain rate to develop contour maps, as shown in Fig. 9. It can be observed from Table 1 and Fig. 9 that DRX fraction of STA alloy is much larger than that of ST alloy at temperatures lower than $1150{ }^{\circ} \mathrm{C}$, while both alloys are comparable above $1150^{\circ} \mathrm{C}$. This signifies that the effect of precipitated particles on the DRX behavior (or PSN effect) was weakened with an increase in deformation temperature. The main cause for this phenomenon can be ascribed to the dissolution of $\mu$ phase and $M_{6} \mathrm{C}$, which results in loss of the PSN effect. As revealed in Fig. 2, dissolution temperature of the second phase in the UNS N10276 alloy is about $1130{ }^{\circ} \mathrm{C}$. Thus, DRX can be significantly promoted through PSN mechanism, when the hot deformation was performed at temperatures $950-1150{ }^{\circ} \mathrm{C}$. As the deformation temperature was higher than $1150{ }^{\circ} \mathrm{C}$, the secondphase particles were completely dissolved, and hence the $\gamma$ matrix of STA alloy could regain same concentrations of Mo, Cr and W elements as ST alloy. Thus, the STA and ST alloys can achieve same initial microstructures and have accordant DRX mechanism during hot deformation without PSN effect. As a result, near-equal DRX fraction could be obtained in both alloys.

\subsection{Influence of Precipitation on Processing Maps of the UNS N10276 Alloy}

\subsubsection{Fundamental Principles of Processing Map}

Processing maps are developed based on the dynamic materials model (DMM), which considers the material as a dissipator of power [29-31]. According to DMM, the total power can be divided into two parts: (1) the power consumption by plastic deformation, most of which is transformed into heat; (2) the power dissipation through microstructural evolution that includes DRV, DRX, void formation and precipitation from metastable phase. The efficiency of power dissipation resulting from microstructural changes in the workpiece can be represented with a dimensionless parameter $(\eta)$, which is given by:

$\eta=\frac{2 m}{m+1}$,

where $m$ is the strain rate sensitivity parameter, which is an important indicator of material property, and could be expressed as: 

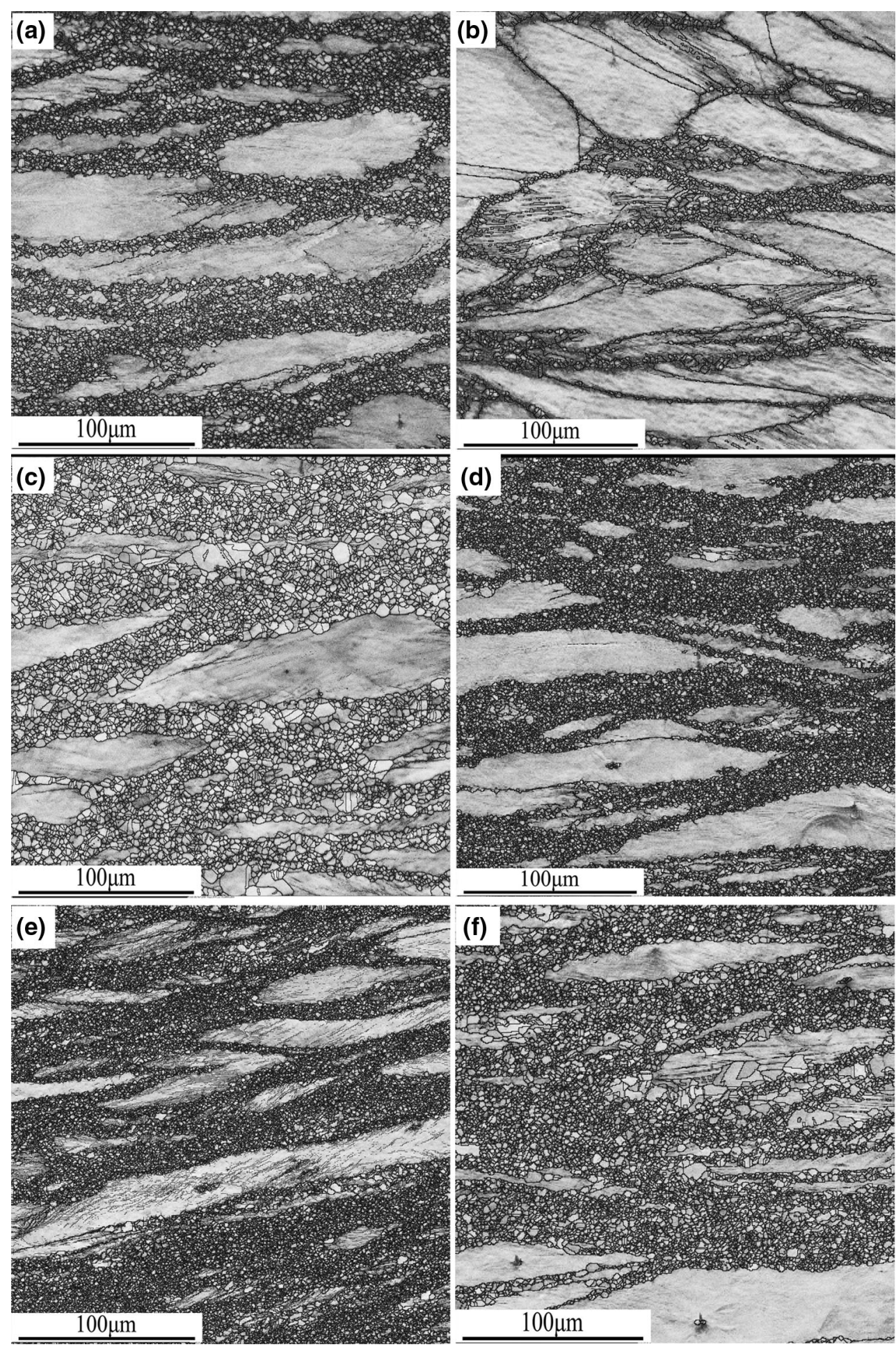

Fig. 7 IQ maps of the solution-treated (ST) UNS N10276 alloy deformed at a $950{ }^{\circ} \mathrm{C}, 0.01 \mathrm{~s}^{-1} ; \mathbf{b} 950{ }^{\circ} \mathrm{C}, 1 \mathrm{~s}^{-1} ; \mathbf{c} 950{ }^{\circ} \mathrm{C}, 10 \mathrm{~s}^{-1} ; \mathbf{d ~} 1000{ }^{\circ} \mathrm{C}$, $1 \mathrm{~s}^{-1}$; e $1000{ }^{\circ} \mathrm{C}, 10 \mathrm{~s}^{-1}$; f $1050{ }^{\circ} \mathrm{C}, 1 \mathrm{~s}^{-1}$

$m=\left[\frac{\partial(\ln \sigma)}{\partial(\ln \dot{\varepsilon})}\right]_{\varepsilon, T}$,

where $\sigma$ is the flow stress, $\dot{\varepsilon}$ is the strain rate, $\varepsilon$ is the amount of strain, and $T$ is the deformation temperature.
The efficiency of power dissipation $(\eta)$ can be plotted against temperature and strain rate to produce power dissipation map depicted in the form of isoefficiency 2D contour map. The different domains exhibited in this map could be correlated with specific microstructures. High 

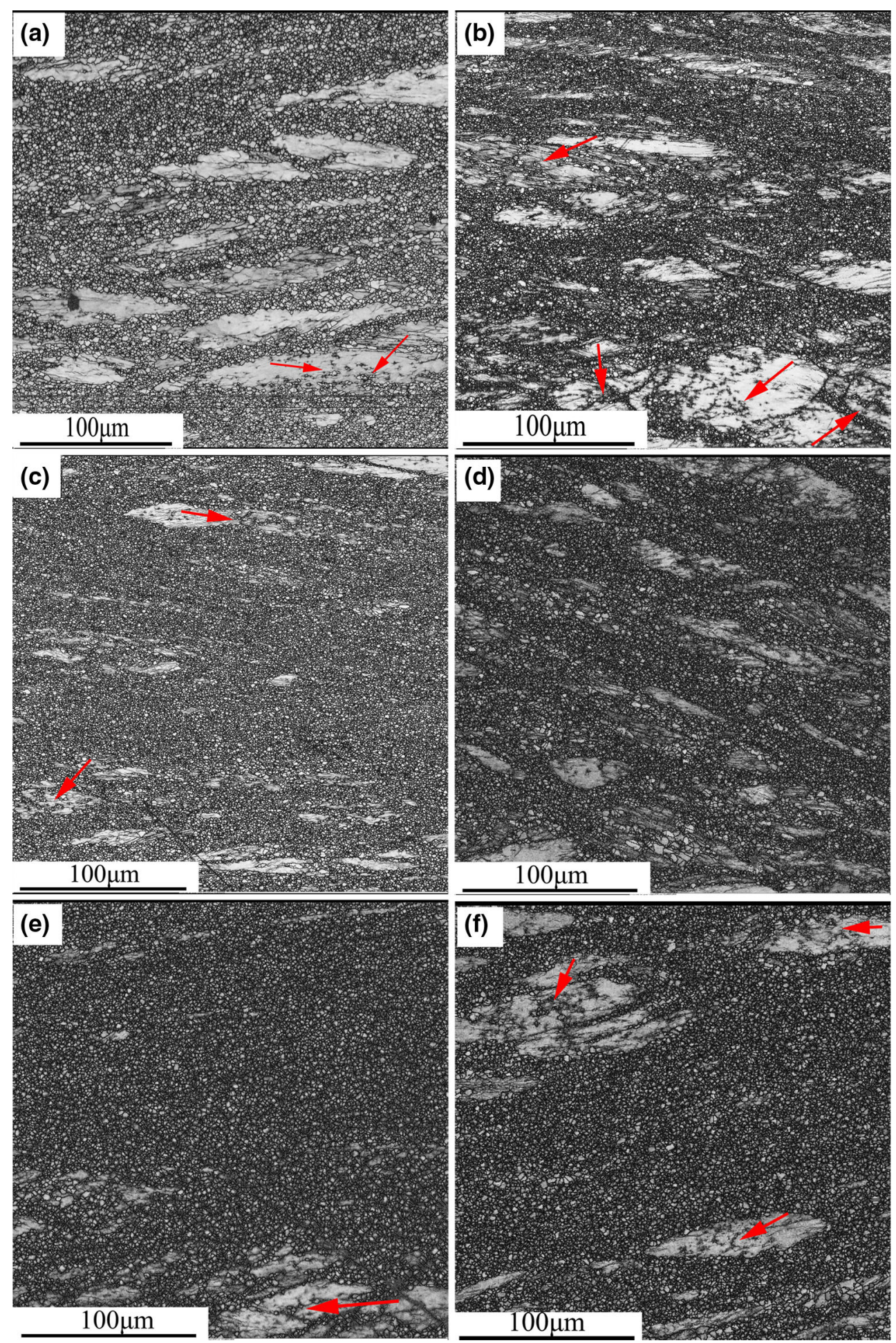

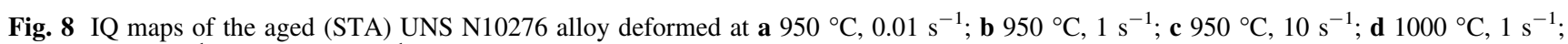
e $1000{ }^{\circ} \mathrm{C}, 10 \mathrm{~s}^{-1} ; \mathbf{f} 1050{ }^{\circ} \mathrm{C}, 1 \mathrm{~s}^{-1}$

efficiencies imply that the microstructure evolves in the most efficient way during hot working. The safe mechanisms of microstructural evolution consist of DRX and DRV, while harmful ones include wedge cracking, void formation and other types of cracking process. Moreover, deformation twinning and shear band formation could also lead to the instable plastic deformation. In order to identify the domains of flow instabilities, the instability criterion 
Table 1 DRX fraction (in pct.) of ST and STA alloys deformed at different temperatures and strain rates

\begin{tabular}{|c|c|c|c|c|c|c|c|}
\hline \multirow[t]{2}{*}{ Strain rate $\left(\mathrm{s}^{-1}\right)$} & \multicolumn{7}{|c|}{ Temperature $\left({ }^{\circ} \mathrm{C}\right)$} \\
\hline & 950 & 1000 & 1050 & 1100 & 1150 & 1200 & 1250 \\
\hline 0.01 & $30.8 / 41.9$ & $34.9 / 49.8$ & $51.3 / 57.2$ & $75.2 / 80.2$ & $86.8 / 85.9$ & $73.9 / 76.4$ & $71.7 / 73.3$ \\
\hline 0.1 & $12.5 / 50.7$ & $39.9 / 58.3$ & $53.2 / 64.3$ & $73.7 / 88.8$ & $89.6 / 90.1$ & $90.3 / 92.5$ & $90.4 / 90.7$ \\
\hline 1 & $17.3 / 30.4$ & $32.4 / 55.4$ & $52.1 / 62.5$ & $65.1 / 75.8$ & $75.9 / 83.5$ & $87.5 / 89.2$ & $90.5 / 91.5$ \\
\hline 10 & $39.5 / 55.6$ & $42.9 / 50.3$ & $56.5 / 68.7$ & $62.8 / 70.4$ & $65.7 / 83.3$ & $84.2 / 86.1$ & $87.4 / 88.3$ \\
\hline
\end{tabular}
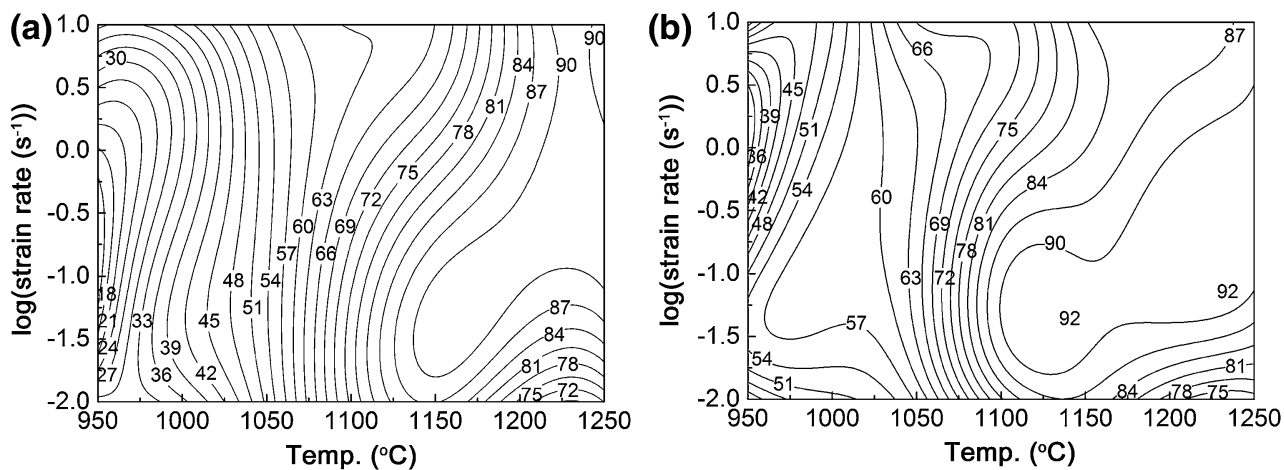

Fig. 9 Contour map of fraction of DRX for a the solution-treated (ST), b aged (STA) UNS N10276 alloys under different deformation conditions. The contour numbers represent fraction of DRX expressed in pct

based on the continuum principles that is applicable to large plastic flow had been proposed [32], and given by another dimensionless parameter $\xi(\dot{\varepsilon})$ :

$\xi(\dot{\varepsilon})=\frac{\partial \ln [m /(m+1)]}{\partial \ln \dot{\varepsilon}}+m \leq 0$.

Processing map can be developed by superimposing the variation of the instability parameter $\xi(\dot{\varepsilon})$ with temperature and strain rate on the power dissipation map at a certain strain. The domains with negative $\xi(\dot{\varepsilon})$ in the processing map are considered as instability domains, in which hot working should be avoided. The optimum hot working parameters can be determined in the stable domains with the highest efficiency of power dissipation. Under the guidance of processing maps, the optimum hot processing domains can be obtained.

\subsubsection{Comparison of Processing Maps Between ST and STA UNS N10276 Alloys}

The values of power dissipation efficiency and instability parameter for the ST and STA alloys were calculated using Eqs. (1) and (3) to develop processing maps at nine different strain levels $(0.1,0.2,0.3,0.4,0.5,0.6,0.7,0.8$ and 0.9 ), which are shown in Figs. 10a-i and 11a-i. The percent efficiency of power dissipation is represented by the contour numbers, and instability domains in processing maps were marked as the shaded areas. In both alloys, a large unstable region develops over a wider temperature and strain rate range at true strain of 0.1 , but its area dramatically reduces with increasing true strain till 0.5 (see Figs. 10a-e, 11a-e). The reason behind this phenomenon is that at initial deformation stage the strain is smaller than the threshold strain for the occurrence of DRX, and the dislocation generation and multiplication are the main hot deformation mechanisms, particularly at low temperatures and high strain rates. Meanwhile, DRV is very sluggish as cross-slip and climb are hindered in the nickel-base alloy due to relatively low stacking fault energy [33], and thus softening effect caused by DRV cannot balance work hardening (WH). In this case, $\mathrm{WH}$ is the predominant microstructure mechanism, which could result in low or negative values of power dissipation as well as ultimately lead to the formation of wider unstable domains. However, once the strain exceeds the critical strain, DRX occurs and dynamic softening takes place, and hence the unstable regions in processing map shrank. It should not be ignored that no trace of unstable flow region was found in the processing maps of STA alloy at true strains $0.2-0.5$, while as for the ST alloy, there still exist instability regions in the processing maps. This signifies that the flow behavior of STA alloy during hot deformation was more stable than that of the ST alloy in the strain range that is often applied to nickel-base superalloy. The reason underlying this 

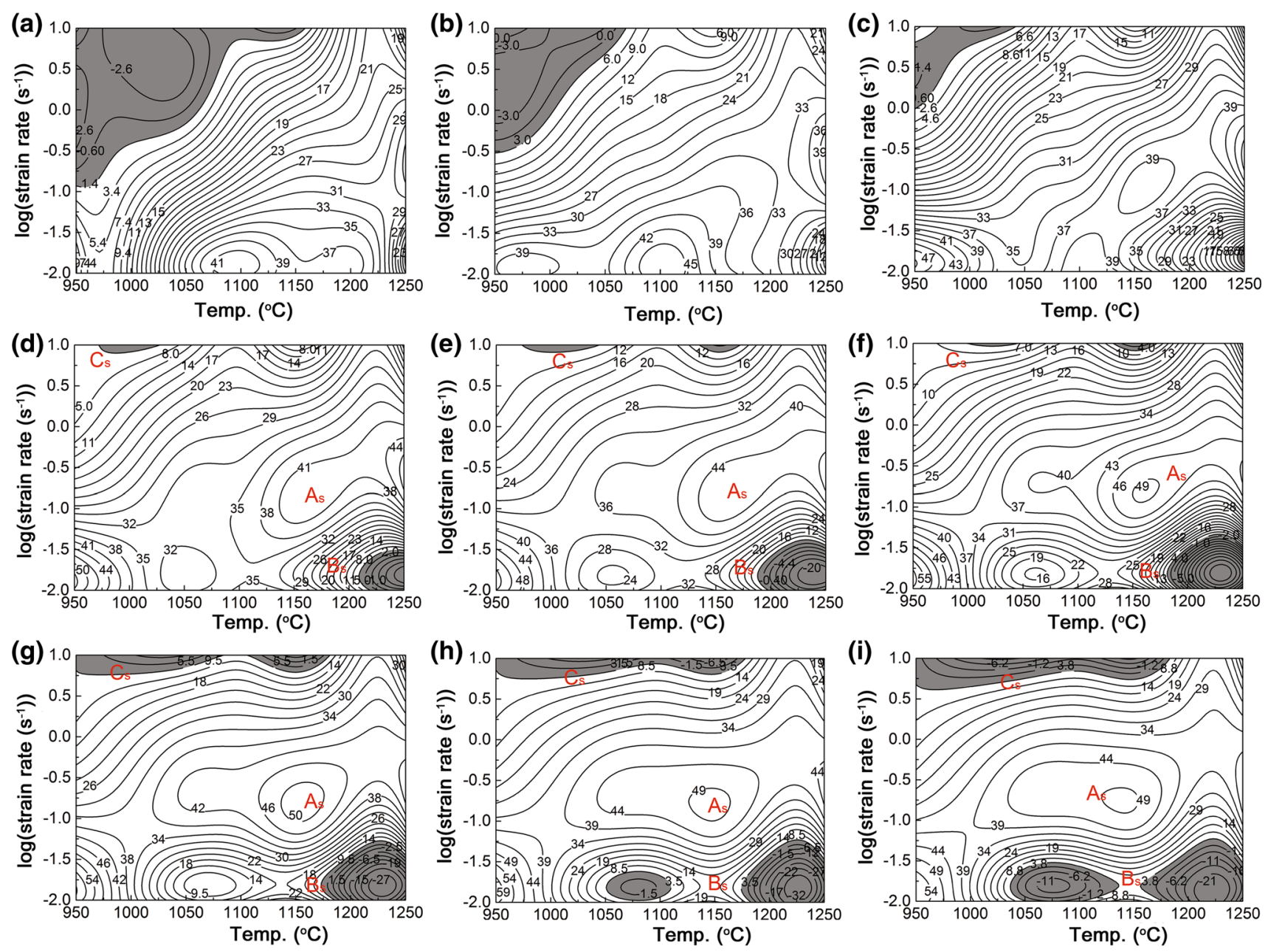

Fig. 10 Processing maps of the solution-treated (ST) UNS N10276 alloy at true strains of a 0.1, b 0.2, c 0.3, d 0.4, e 0.5 , f 0.6, g 0.7, h $0.8, \mathbf{i} 0.9$

interesting result could be also attributed to the PSN effect that can effectively increase the extent of DRX. It is well known that DRX can enhance the intrinsic workability of the metals or alloys [34]. Therefore, the presence of the $\mu$ phase and $M_{6} \mathrm{C}$ improved the hot workability of the alloy UNS N10276 to some degree.

In order to safely perform secondary thermomechanical processing, the processing map obtained at higher strains is universally employed to delineate the safe domain and design optimum hot working parameters. Therefore, in the present investigation, the processing maps developed at high strain of 0.9 were adopted to identify the hot working window of the ST and STA alloys. As shown in Figs. 10i and $11 \mathrm{i}$, based on the dominant microstructural mechanisms the processing maps of both alloys can be broadly segmented into three characteristic domains, which were marked with $A_{s}, B_{s}$ and $C_{s}$ for the ST alloy as well as with $A_{a}, B_{a}$ and $C_{a}$ for the STA alloy, respectively. Table 2 shows the different domains in the processing maps of both alloys. In the case of the ST alloy, the stable domain $A_{s}$ starts to appear in the map at true strain of 0.4 (see Fig. 10d), and its temperature range is extended from $1100-1220{ }^{\circ} \mathrm{C}$ to $1000-1220{ }^{\circ} \mathrm{C}$ upon deformation to the true strain of 0.9. Meanwhile, its peak efficiency of power dissipation $(\eta)$ is increased form 41 to $49 \%$. Besides, there are some narrower stable domains with high efficiencies in the maps of ST alloy, such as the deformation temperature spectrum from 950 to $1000{ }^{\circ} \mathrm{C}$ and strain rate spectrum from 0.01 to $0.1 \mathrm{~s}^{-1}$. Nevertheless, the processing parameter range of this deformation zone is narrower, which is not beneficial to the actual operation. In the case of the STA alloy, the stable domain $A_{a}$ starts to appear at true strain of 0.3 with a peak efficiency of $43 \%$ (see Fig. 11c). This domain gets developed further at higher strains by expanding the temperature interval from $1085-1220{ }^{\circ} \mathrm{C}$ to $1025-1220^{\circ} \mathrm{C}$, and the peak efficiency significantly increases to $58 \%$ at true strain of 0.9 . Just Like the ST alloy, there also exist some narrower stable domains in the maps of the STA alloy, in which hot working is not recommended. Compared to other stable regions, the 

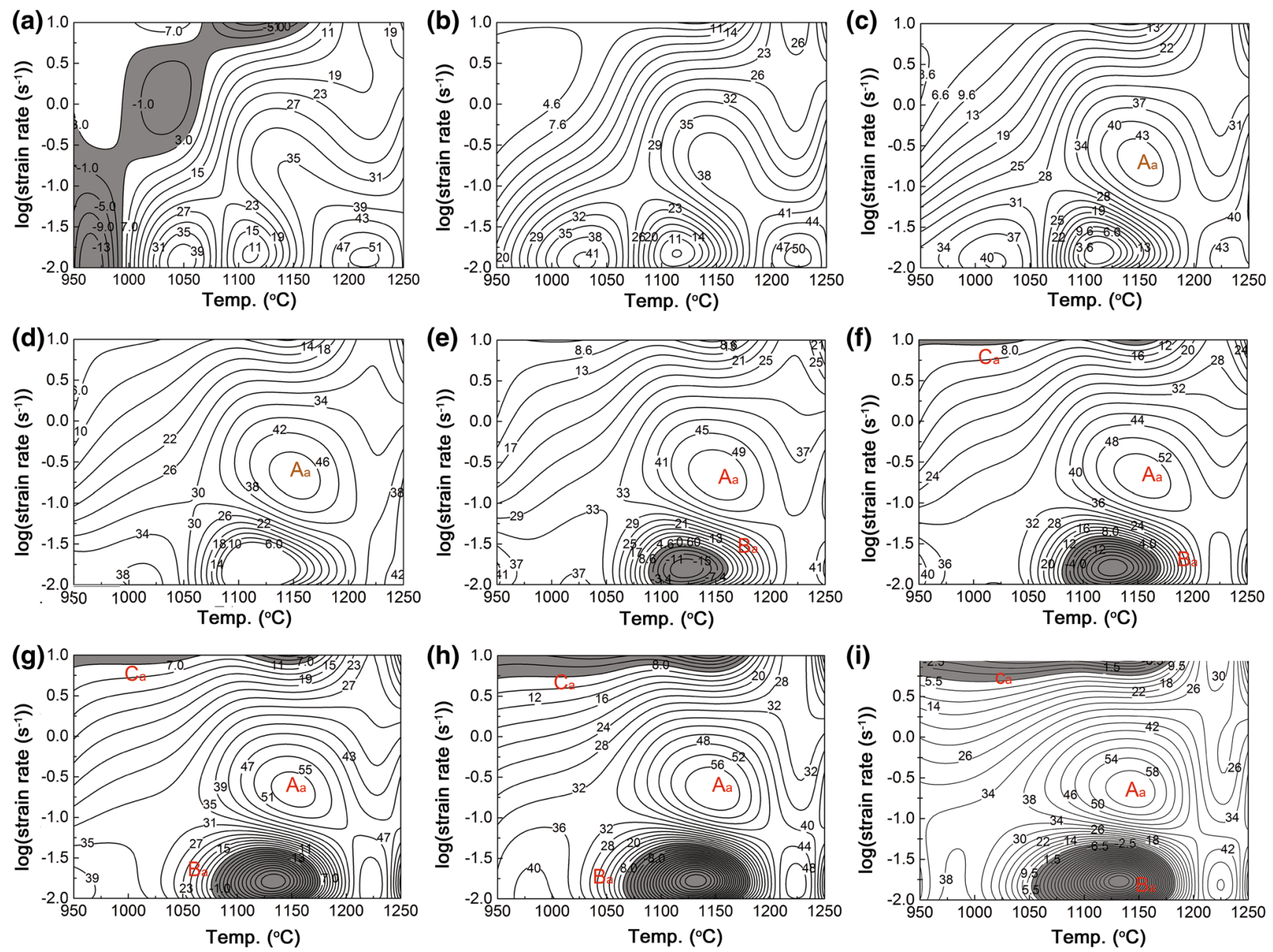

Fig. 11 Processing maps of the aged (STA) UNS N10276 alloy at true strains of a $0.1, \mathbf{b} 0.2$, c 0.3 , d 0.4 , e 0.5, f 0.6, g 0.7 , h $0.8, \mathbf{i} 0.9$

Table 2 Different domains in the processing maps of ST and STA alloys

\begin{tabular}{llccc}
\hline Alloys & Domains & Temperature $\left({ }^{\circ} \mathrm{C}\right)$ & Strain rate $\left(\mathrm{s}^{-1}\right)$ & Efficiency $(\eta) \%$ \\
\hline ST & $A_{s}$ (stable region) & $1000-1220$ & $0.07-2.2$ & $30-49$ \\
& $B_{s}$ (instability region) & $1035-1250$ & $0.01-0.06$ & $\leq 0$ \\
& $C_{s}$ (instability region) & $950-1180$ & $5-10$ & $\leq 0$ \\
STA & $A_{a}$ (stable region) & $1025-1220$ & $0.07-2.5$ & $30-58$ \\
& $B_{a}$ (instability region) & $1050-1195$ & $0.01-0.058$ & $\leq 0$ \\
& $C_{a}$ (instability region) & $950-1183$ & $5.6-10$ & $\leq 0$ \\
\hline
\end{tabular}

efficiencies of power dissipation in both domain $A_{s}$ and $A_{a}$ are relatively higher, and the area of these two stability domains is larger. Thus, the processing parameters in the actual hot working should be selected in these types of domains. In many of the metallic alloys, it is generally believed that the higher peak efficiency can result in a better workability of materials. Accordingly, the hot workability of STA alloy could be considered to be superior to that of ST alloy, although the temperature range of the domain $A_{a}$ is slightly narrower than that of the domain $A_{s}$. In general, microstructure evolution in the stable domain may be DRX, DRV and superplasticity. It is widely acknowledged that high peak efficiency is often associated with DRX or superplasticity [35]. However, the superplasticity is not achievable for the UNS N10276 alloy studied. This is because for purpose of achieving 
superplasticity, the material must possess very fine grain size $(5-10 \mu \mathrm{m})$ and high strain rate sensitivity, and the loading process should be performed at the strain rate lower than $0.01 \mathrm{~s}^{-1}$ [36]. Therefore, DRX could be considered as main microstructure evolution mechanism in the preferential deformation regions, such as domain $A_{s}$ and $A_{a}$ in maps of the ST and STA alloys.

As far as the instability regions were concerned, the area of unstable domain $B_{a}$ and $C_{a}$ in the processing maps of the STA alloy is smaller than that of the instable zone $B_{s}$ and $C_{s}$ in the maps of the ST alloy (see Table 2). This suggests that the extent of flow instability during hot deformation of the alloy UNS N10276 was decreased by aging treatment that gives rise to the precipitation of $\mu$ phase and $M_{6} \mathrm{C}$ carbide. It also can be understood that the existence of the precipitates alleviated the degree of instability by facilitating DRX. To further understand the mechanism of microstructure evolution and evaluate the predictability of processing maps developed for the ST and STA alloys, the microstructures of the samples compressed under the specific parameters in the different deformation zones of the processing maps were characterized by EBSD technique.

The microstructures of the specimens deformed at the different domains in the processing maps of the ST and STA alloys are shown in Figs. 12 and 13, respectively. From Fig. 12, it can be seen that after the specimens of the ST alloy were compressed at $1100{ }^{\circ} \mathrm{C} / 0.1 \mathrm{~s}^{-1}$ (Fig. 12a) and $1150{ }^{\circ} \mathrm{C} / 1 \mathrm{~s} \mathrm{~s}^{-1}$ (Fig. 12c) in the domain $A_{s}$ as well as at $1150{ }^{\circ} \mathrm{C} / 10 \mathrm{~s}^{-1}$ (Fig. 12d) in the domain $C_{s}$, the microstructures were composed of fine DRX grains and coarse deformed parent grains. However, after compression under the same deformation conditions as that of the ST alloy, the STA alloy exhibited finer and more homogeneous DRX grains (see Fig. 13a, c, d), showing no trace of un-recrystallized grains. This agrees well with the results obtained from comparing DRX fraction of both alloys that the extent of DRX in the STA alloy is much larger than that of the ST alloy below $1150{ }^{\circ} \mathrm{C}$ and at strain rates higher than $0.1 \mathrm{~s}^{-1}$ (see Table 1). It further demonstrates that the presence of second-phase particles can increase the degree of DRX and help the alloy to obtain desired microstructures. As expected, when the hot deformation was carried out above $1150{ }^{\circ} \mathrm{C}$, DRX grain structures in both alloys completely replaced the initial deformed grains. Since the deformation temperatures were higher than dissolution temperature of the second phase, the precipitates were almost completely dissolved and the grain growth was apparently promoted without particle restricting. It is a common knowledge that DRX is easier to occur at high temperature and low strain rate. Indeed, from the microstructural point of view, it seems that both alloys have undergone complete DRX after deformation at temperatures higher than $1150{ }^{\circ} \mathrm{C}$ (see Figs. $12 \mathrm{e}-\mathrm{i}, 13 \mathrm{e}-\mathrm{i}$ ). However, EBSD analysis reveals that the fractions of DRX are lower than $93 \%$ for the specimens deformed above $1150{ }^{\circ} \mathrm{C}$ and at various strain rates (see Table 1). It is unexpected that DRX fractions of the samples compressed at 1200 and $1250{ }^{\circ} \mathrm{C}$ with strain rate of $0.01 \mathrm{~s}^{-1}$ are smaller than $77 \%$, while the fractions are larger than $84 \%$ at the strain rates higher than $0.01 \mathrm{~s}^{-1}$. This may be because DRX grains had strong tendency to coarsen at higher temperatures and lower strain rates, and could suffer from the severe plasticity deformation with increasing strain. Thus, unlike the grain obtained through static recrystallization, the coarse DRX grain is not strain-free. Once the strain imposed on primary DRX grain exceeds critical strain for DRX, circulating recrystallization could occur. As a result, the deformed DRX grain was not considered as fresh recrystallized grain during EBSD analysis, leading to a decrease in calculated fraction of DRX. This phenomenon has not yet been reported by any investigators. Thus, the values of DRX fractions obtained from this study cannot be compared to any available data obtained on a similar alloy under identical hot deformation conditions.

Based on the aforementioned discussion, it might be concluded that the presence of TCP $\mu$ phase and $M_{6} \mathrm{C}$ carbide can effectively promote DRX, by which the STA alloy can achieve finer and more uniform grain structure compared to ST alloy. Similar effect of delta phase $\left(\mathrm{Ni}_{3} \mathrm{Nb}\right)$ on hot deformation of Inconel 718 superalloy has been reported by Wen et al. [23], who pointed out that delta phase could stimulate the occurrence of dynamic recrystallization and promote the dynamic softening. In the present investigation, we found that aging treatment can also increase the peak efficiency of power dissipation and reduce the extent of instability. It was demonstrated that precipitation of the second phases was conducive to the hot workability of UNS N10276 alloy aged at $870{ }^{\circ} \mathrm{C}$ for $24 \mathrm{~h}$. It should be noted that in the present study, we have not examined the effect of different amounts of precipitates on the hot deformation behavior of the alloy, since it is not the purpose of this paper. However, the excessive precipitated phase, such as the brittle and hard TCP $\mu$ phase, could weaken the compatibility of $\gamma$-matrix and the second phase, resulting in the poor workability. Therefore, the influence of initial aging time on the hot workability of the alloy should be considered and will be the subject of a forthcoming paper.

\section{Conclusions}

The hot deformation behavior of aged nickel-base UNS N10276 alloy was studied and compared with that of solution-treated UNS N10276 alloy in the temperature 

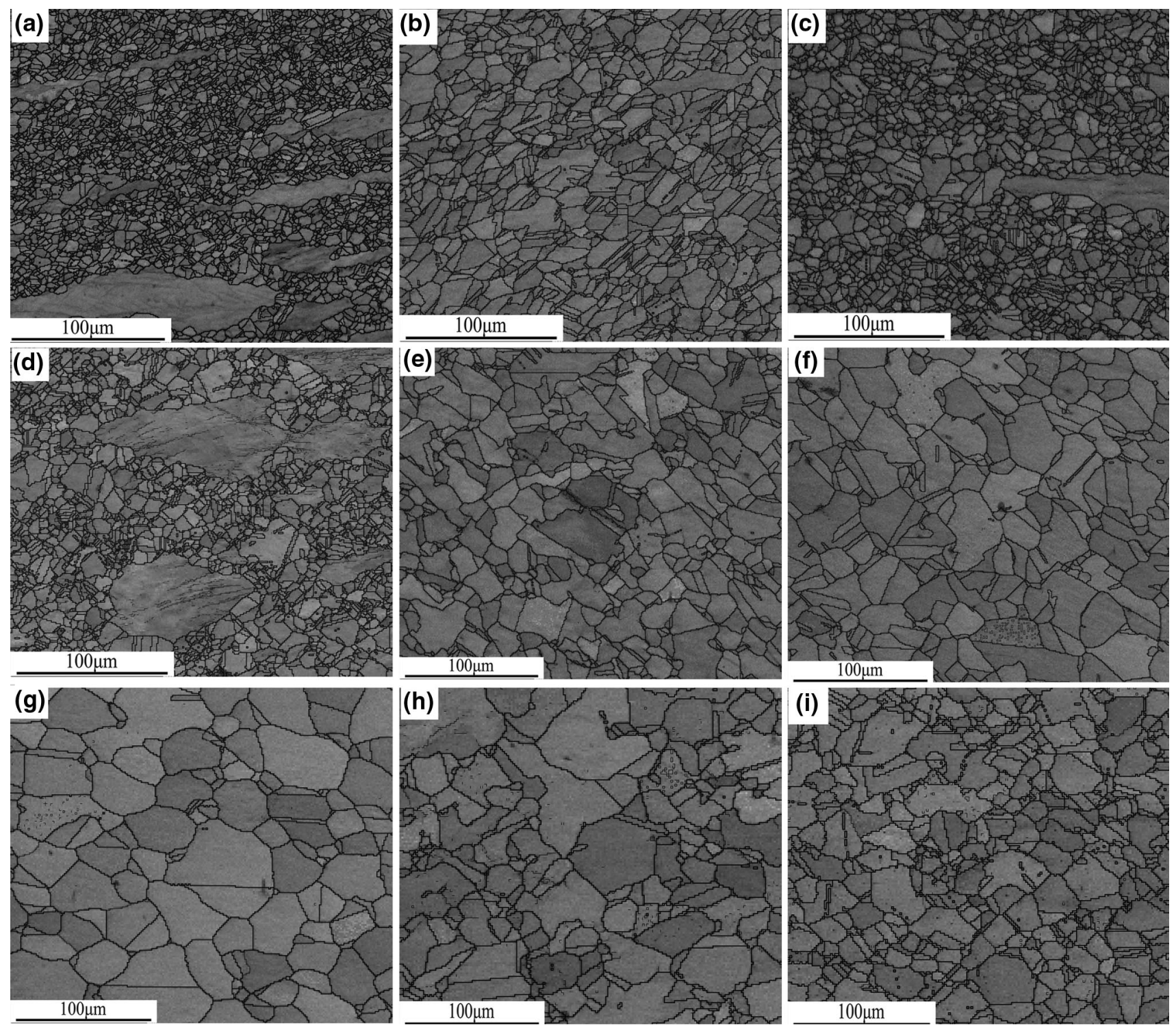

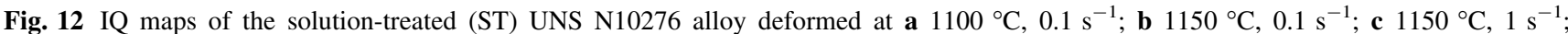
d $1150{ }^{\circ} \mathrm{C}, 10 \mathrm{~s}^{-1}$; e $1200{ }^{\circ} \mathrm{C}, 0.01 \mathrm{~s}^{-1}$; f $1200{ }^{\circ} \mathrm{C}, 0.1 \mathrm{~s}^{-1} ; \mathbf{g} 1200{ }^{\circ} \mathrm{C}, 1 \mathrm{~s}^{-1} ; \mathbf{h ~} 1250{ }^{\circ} \mathrm{C}, 0.01 \mathrm{~s}^{-1} ; \mathbf{i} 1250{ }^{\circ} \mathrm{C}, 1 \mathrm{~s}^{-1}$

range from 950 to $1250{ }^{\circ} \mathrm{C}$ and strain rates range of $0.01-10 \mathrm{~s}^{-1}$. The second phases were characterized by SEM, TEM and EPMA, and DRX structures of the specimens deformed were examined by EBSD. The effect of precipitation on the flow behavior, processing maps and microstructural evolution was investigated in detail. The following conclusions can be drawn from this work:

1. The precipitated phases in the aged alloy UNS N10276 were identified as TCP $\mu$ phase and $M_{6} \mathrm{C}$ carbide, both of which are enriched in Mo and Ni. The $\mu$ phase precipitates were much more abundant than $M_{6} \mathrm{C}$ carbide precipitates. The nucleation of $\mu$ phase took place in both grain boundary and grain interior, while the $M_{6} \mathrm{C}$ carbide precipitated primarily on grain boundary and twin boundaries.

2. The precipitates present in the aged UNS N10276 alloy significantly promoted strain softening after peak stress at temperatures lower than $1150{ }^{\circ} \mathrm{C}$ and strain rates higher than $0.01 \mathrm{~s}^{-1}$. This was caused by the particle-stimulated nucleation (PSN) mechanisms and depletion in strengthening elements, such as Mo and $\mathrm{W}$ in the $\gamma$-matrix.

3. The precipitated phases facilitated dynamic recrystallization by PSN mechanisms at temperatures lower than $1150{ }^{\circ} \mathrm{C}$, which resulted in the larger fraction of DRX as well as finer and more uniform grain structure in the aged alloy compared to the solution-treated 

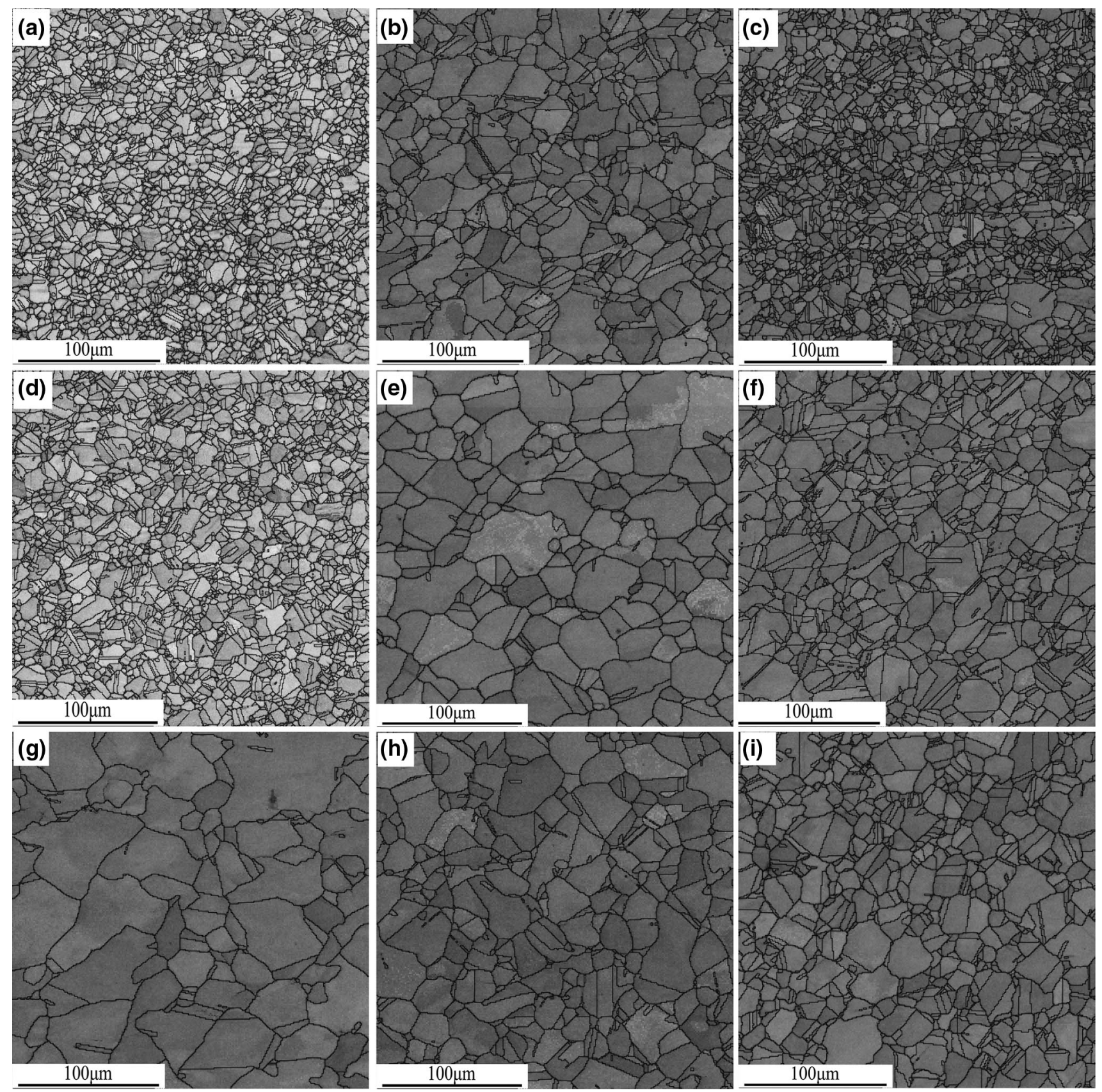

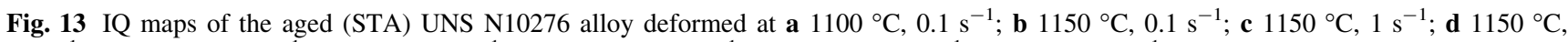
$10 \mathrm{~s}^{-1}$; e $1200{ }^{\circ} \mathrm{C}, 0.1 \mathrm{~s}^{-1} ; \mathbf{f} 1200{ }^{\circ} \mathrm{C}, 1 \mathrm{~s}^{-1} ; \mathbf{g} 1250{ }^{\circ} \mathrm{C}, 0.01 \mathrm{~s}^{-1} ; \mathbf{h} 1250{ }^{\circ} \mathrm{C}, 0.1 \mathrm{~s}^{-1} ; \mathbf{i} 1250{ }^{\circ} \mathrm{C}, 1 \mathrm{~s}^{-1}$

alloy. The DRX fractions of both alloys were comparable above $1150{ }^{\circ} \mathrm{C}$ resulting from dissolution of precipitated phases.

4. Comparison of processing maps between solutiontreated and aged UNS N10276 alloys revealed that aging treatment increased the peak efficiencies of power dissipation and reduced the extent of instability. Moreover, aging treatment eliminated the instability regions of processing maps at true strains of $0.2-0.5$. It was demonstrated that to a certain degree, precipitation of the secondary phases was conducive to the hot workability of UNS N10276 alloy aged at $870{ }^{\circ} \mathrm{C}$ for $24 \mathrm{~h}$.

Acknowledgements This work was financially supported by the Subproject of National Science and Technology Major Project of China (Grant No. 2015ZX06002001-001). The authors thank Min Liu and Huanling Wang for preparing samples for EBSD and TEM analysis and thank Nan $\mathrm{Li}$ and Zhe Wang for their help with hot compression tests. 


\section{References}

[1] E.X. Pu, W.J. Zheng, Z.G. Song, H. Feng, H. Dong, J. Alloys Compd. 694, 617 (2017)

[2] Z. Li, J.H. Han, J.J. Lu, J.M. Chen, J. Alloys Compd. 619, 754 (2015)

[3] Y.Z. Miao, Dissertation, University of Yunnan University (2016)

[4] M. Raghavan, B.J. Berkowitz, J.C. Scanlon, Metall. Trans. A 13, 979 (1982)

[5] C.M.F. Rae, R.C. Reed, Acta Mater. 49, 4113 (2001)

[6] M. Simonetti, P. Caron, Mater. Sci. Eng. A 254, 1 (1998)

[7] J.I. Akhter, M.A. Shaikh, M. Ahmad, M. Iqbal, K.A. Shoaib, W. Ahmad, J. Mater. Sci. Lett. 20, 333 (2001)

[8] L. Yang, G.N. Zhu, J.X. Dong, M.C. Zhang, Proc. Eng. 27, 1008 (2012)

[9] J.X. Liu, J.X. Zhang, Y.L. Lu, Acta Metall. Sin. 49, 763 (2013). (in Chinese)

[10] Y. Wang, L. Zhen, W.Z. Shao, J. Alloys Compd. 474, 341 (2009)

[11] Z.X. Shi, X.F. Yan, C.H. Duan, J. Alloys Compd. 652, 30 (2015)

[12] K.A. Babu, S. Mandal, A. Kumar, C.N. Athreya, B.D. Boer, V.S. Sarma, Mater. Sci. Eng. A 664, 177 (2016)

[13] S.L. Guo, D.F. Li, H.J. Pen, Q.M. Guo, J. Hu, J. Nucl. Mater. 410, 52 (2011)

[14] Y. Liu, R. Hu, J.S. Li, H.C. Kou, H.G. Li, H. Chang, H.Z. Fu, Mater. Sci. Eng. A 497, 283 (2008)

[15] M. Aghaie-Khafri, N. Golarzi, Mater. Sci. Eng. A 486, 641 (2008)

[16] E.X. Pu, W.J. Zheng, J.Z. Xiang, Z.G. Song, H. Feng, Y.L. Zhu, Acta Metall. Sin. (Engl. Lett.) 27, 313 (2014)

[17] E.X. Pu, W.J. Zheng, Z.G. Song, H. Feng, Y.L. Zhu, J. Mater. Eng. Perform. 24, 3897 (2015)

[18] X.X. Yu, Y.R. Zhang, D.F. Yin, Z.M. Yu, S.F. Li, Acta Metall. Sin. (Engl. Lett.) 28, 817 (2015)
[19] Y. Zhang, H.L. Sun, A.A. Volinsky, B.H. Tian, Z. Chai, P. Liu, Y. Liu, Acta Metall. Sin. (Engl. Lett.) 29, 422 (2016)

[20] C. Zhang, L.W. Zhang, W.F. Shen, M.F. Li, S.D. Gu, J. Mater. Eng. Perform. 24, 149 (2015)

[21] Y.H. Kong, P.P. Chang, Q. Li, L.X. Xie, S.G. Zhu, J. Alloys Compd. 622, 738 (2015)

[22] J.X. Yang, Q. Zheng, X.F. Sun, H.R. Guan, Z.Q. Hu, Mater. Sci. Eng. A 465, 100 (2007)

[23] D.X. Wen, Y.C. Lin, J. Chen, X.M. Chen, J.L. Zhang, Y.J. Liang, L.T. Li, J. Alloys Compd. 618, 372 (2015)

[24] Y.C. Lin, D.G. He, M.S. Chen, X.M. Chen, C.Y. Zhao, X. Ma, Z.L. Long, Mater. Des. 97, 13 (2016)

[25] S.Y. Park, W.J. Kim, J. Mater. Sci. Technol. 32, 660 (2016)

[26] J.J. Jonas, X. Quelennec, L. Jiang, É. Martin, Acta Mater. 57, 2748 (2009)

[27] H. Mirzadeh, J.M. Cabrera, A. Najafizadeh, Acta Mater. 59, 6441 (2011)

[28] S.S. Satheesh Kumar, T. Raghu, P.P. Bhattacharjee, G. Appa Rao, U. Borah, J. Alloys Compd. 681, 28 (2016)

[29] N. Srinivasan, Y.V.R.K. Prasad, Metall. Mater. Trans. A 10, 2275 (1994)

[30] E.X. Pu, W.J. Zheng, J.Z. Xiang, Z.G. Song, J. Li, Mater. Sci. Eng. A 598, 174 (2014)

[31] D.G. He, Y.C. Lin, M.S. Chen, J. Chen, D.X. Wen, X.M. Chen, J. Alloys Compd. 649, 1075 (2015)

[32] A. Chiba, S.H. Lee, H. Matsumoto, M. Nakamura, Mater. Sci. Eng. A 513-514, 286 (2009)

[33] N. Dudova, A. Belyakov, T. Sakai, R. Kaibyshev, Acta Mater. 8, 3624 (2010)

[34] S. Mandal, A.K. Bhaduri, V.S. Sarma, Metall. Mater. Trans. A 42, 1062 (2011)

[35] F.S. Qu, Z.Y. Reng, R.R. Ma, Z.H. Wang, D.M. Chen, J. Alloys Compd. 663, 552 (2016)

[36] F. William, J. Hashemi, Foundations of Materials Science and Engineering (China Machine Press, Beijing, 2011) 